\title{
omportamento do Consumidor e a Escolha das Destinações Turísticas
}

\author{
Fátima Guardani' \\ Jorge Aruca ${ }^{2}$ \\ Mônica Araujo
}

RESUMO: Este artigo analisa como o comportamento do consumidor influencia na escolha de um produto turistico. Apresenta o modelo do processo de decisão de compra sugerido por Engel, Blackwell e Miniardi e faz a relação deste com o turismo. Conclui analisando os vários aspectos que interferem na decisão por uma viagem.

PALAVRAS-CHAVE: Comportamento do consumidor; produto turístico; processo de decisão de compra.

ABSTRACT: This article analyses the consumer behavior while choosing a touristic product. It presents the buying processmodelsuggested by Engel, Blackwell and Miniardi and relat it to tourism. In conclusion, the article analyses various aspects which interfere in the choice of a travel.

KEY WORDS: Consumer behavior; touristic product; buying process model.

1. Bacharel em Ciências Sociais pela Faculdade de Filosofia, Letras e Ciências Humanas da USP. Mestranda em Turismo e Lazer na Escola de Comunicaçōes e Artes da USP.

End. para corresp.: Rua Passo da Pátria 1.240, apto. 51 - 05085-000 - São Paulo - SP - Brasil.

2 Engenheiro em Telecomunicações e Mestre em Ciências Técnicas pelo Instituto Eletrotécnico em Comunicaçōes de Novoslbirak - Rússia. Mestrando em Administração deEmpresas na Faculdade de Economia e Administração da USP. End. para corresp.: CRUSP - Bloco G, apto. 207, Cidade Universitária - 05508-900 - São Paulo - SP - Brasil

E-mail: jamge@spider.usp.br.

3. Bacharel em Turismo pela Universidade Federal

e Astes da USP.

End. para corresp.:

Fax: (011) 259.0930. 


\section{Introduçāo}

O estudo do comportamento do consumidor engloba diferentes aspectos que determinam os motivos pelos quais os indivíduos compram bens e serviços, assim como as formas e as características das suas compras. Segundo Engel et al. (1995), o comportamento do consumidor refere-se àquelas atividades que estão diretamente envolvidas na obtenção, consumo e disposição de produtos e serviços, incluindo os processos decisórios que precedem e seguem essasações. Nesse sentido, o estudo do comportamento do consumidor pode identificar as possíveis estratégias de marketing de produtos e serviços a serem utilizadas, a partir do conhecimento das diferentes variáveis que envolvem o processo de compras.

No turismo, esse processo ocorre de forma diferenciada devido à natureza do produto turístico, Entende-se por produto turístico (Acerenza, 1991) o conjunto de prestações, materiais ou imateriais, que se oferecem com o propósito de satisfazer os desejos ou as expectativas do turista. É composto por três elementos: atrativos, facilidades e acesso, conforme Quadro 1.

Assim sendo, sob a ótica do consumidor o produto turístico divide-se em:

- atrativos: correspondem aos principais elementos que determinam a escolha da destinação pelo turista. São os atributos naturais, culturais e eventos programados;

- facilidades:permitem a permanência do turista na localidade visitada. Embora muitas vezes não sejam responsáveis pela geração de fluxos turísticos, as instalações e os serviços facilitam o alojamento, a alimentação do visitante, bem como seu entretenimento;

- acesso: são as vias e os meios de transportes disponíveis que possibilitam a locomoção do turista até o local desejado.

O produto turístico apresenta características distintas dos demais produtos industrializados e de comércio, além de diferenciar-se da prestação de outros serviços (Quadro 2).

Esses atributos são responsáveis, de uma forma geral, pela distinção entre os produtos turísticos e demais tipos de produtos.

Para definir estratégias de marketing, faz-se necessário entender a percepção que os indivíduos têm a respeito dos produtos turísticos, das áreas de destinação, meios de transportes, distâncias a serem percorridas, propaganda; como decidem sobre as viagens; como a personalidade pode afetar essas decisões; como as motivações influenciam; como são formadas as atitudes e como os vários grupos afetam os comportamentos relacionados às viagens (Moutinho, 1987). Portanto, verifica-se a importância da realização de pesquisas e estudos considerando a complexidade dos fatores envolvidos no comportamento do consumidor de produtos turísticos.
QUADRO I-COMPONENTES DO PRODUTO TURÍSTICO

\begin{tabular}{|c|c|c|}
\hline \multirow{2}{*}{ Atrativos } & Sitios & $\begin{array}{l}\text { Naturais } \\
\text { Usos e costumes } \\
\text { Infra-estrutura }\end{array}$ \\
\hline & Eventos & $\begin{array}{l}\text { Feiras e exposiçōes } \\
\text { Congressos e convençōes } \\
\text { Acontecimentos especiais }\end{array}$ \\
\hline \multirow{4}{*}{$\begin{array}{l}\text { Facilidades } \\
\text { que } \\
\text { permitem a } \\
\text { permanência }\end{array}$} & Alojamento & $\begin{array}{l}\text { Hotëis } \\
\text { Motëis } \\
\text { Albergues } \\
\text { Campings } \\
\text { Condominios }\end{array}$ \\
\hline & Alimentação & $\begin{array}{l}\text { Restaurantes } \\
\text { Confeitarias } \\
\text { Bares }\end{array}$ \\
\hline & Entretenimento & $\begin{array}{l}\text { Distraçōes } \\
\text { Diversōes } \\
\text { Esportes }\end{array}$ \\
\hline & Complementares & $\begin{array}{l}\text { Passeios locais } \\
\text { Excursōes }\end{array}$ \\
\hline $\begin{array}{l}\text { Acesso que } \\
\text { permite o } \\
\text { deslocamento } \\
\text { até o lugar }\end{array}$ & Transporte & $\begin{array}{l}\text { Aéreo } \\
\text { Terrestre } \\
\text { Maritimo } \\
\text { Fluvial }\end{array}$ \\
\hline
\end{tabular}

Fonte: Acerenza (1991: 8). 


\section{QUADRO 2 - CARACTERISTICAS QUE DISTINGUEM O PRODUTO TURISTICO DOS} DEMAIS BENS/PRODUTOS

\begin{tabular}{|c|c|}
\hline Bens/Produtos & Produlo Turistico \\
\hline $\begin{array}{l}\text { - É material, tangivel e pode ser } \\
\text { avaliado previamente por uma } \\
\text { amostra. }\end{array}$ & $\begin{array}{l}\text { - É material e intangivel, não pode } \\
\text { ser visto antes da compra. }\end{array}$ \\
\hline $\begin{array}{l}\text { - A produção ocorre, em geral, } \\
\text { anteriormente ao consumo e em } \\
\text { local distinto. }\end{array}$ & $\begin{array}{l}\text { - A produção e o consumo } \\
\text { ocorrem simultaneamente e no } \\
\text { mesmo lugar. }\end{array}$ \\
\hline - Em geral, pode ser transportado. & $\begin{array}{l}\text { - É necessário que o turista se } \\
\text { desloque até o produto, que não } \\
\text { pode ser transportado. }\end{array}$ \\
\hline $\begin{array}{l}\text { - Podem ser estocados e vendidos } \\
\text { a posteriori. }\end{array}$ & $\begin{array}{l}\text { - Não pode ser estocado, se não } \\
\text { for vendido, implica perdas. }\end{array}$ \\
\hline - Passivel de controle de qualidade. & $\begin{array}{l}\text { - Dificilmente sua qualidade pode } \\
\text { ser controlada. }\end{array}$ \\
\hline $\begin{array}{l}\text { - Não há, necessariamente, } \\
\text { complementaridade entre os } \\
\text { produtos. }\end{array}$ & $\begin{array}{l}\text { - Existe complementaridade entre } \\
\text { os elementos que compóem o } \\
\text { produto turistico. }\end{array}$ \\
\hline $\begin{array}{l}\text { - Demonstra ocorrência menor de } \\
\text { sazonalidade. }\end{array}$ & - É mais susceptivel à sazonalidade. \\
\hline $\begin{array}{l}\text { - É mais fácil de ser adaptado às } \\
\text { alteraçōes do público consumidor. }\end{array}$ & $\begin{array}{l}\text { - É estático, ou seja, é impossivel } \\
\text { mudar sua localização e é difícil } \\
\text { alterar suas caracteristicas em } \\
\text { função da demanda. }\end{array}$ \\
\hline $\begin{array}{l}\text { - Passa a ser uma propriedade do } \\
\text { consumidor. }\end{array}$ & $\begin{array}{l}\text { - Não passa a ser possuído pelo } \\
\text { consumidor através da compra, o } \\
\text { turista não traz consigo o hotel, mas } \\
\text { sim fotos e recordações. }\end{array}$ \\
\hline $\begin{array}{l}\text { - É passivel de ser transferido } \\
\text { através de venda ou doação a } \\
\text { outro consumidor. }\end{array}$ & $\begin{array}{l}\text { - Uma vez adquirido, não pode ser } \\
\text { vendido novamente pelo turista. }\end{array}$ \\
\hline
\end{tabular}

Fonte: Ruschmann (1991).

\section{Comportamento do Consumidor - Fatores que Influenciam na Escolha da Destinaçāo Turística}

Os modelos do processo de decisão (Benneth, 1975; Kotler, 1994) descrevem como a informação é adquirida pelo consumidor e sistematizada para a realização da tomada de decisão. A maioria desses modelos apresentam cinco estágios diferentes no processo decisório: identificação do problema, busca de informações, avaliação de alternativas, escolha e processo pós-escolha. Já Engel et al. (1995) propõem um modelo do processo de decisão de compra que implica sete estágios:

- reconhecimento das necessidades: inicia-se quando o consumidor reconhece um problema/necessidade e percebe a diferença entre seu estado real e um estado desejado/ideal;

- busca de informações: neste estágio, procuram-se informações que estão armazenadas na memória (fontes internas) ou aquisições de informações no ambiente (fontes externas);

- avaliação de alternativas pré-compra: avaliam-se as opções em termos de benefícios esperados e limita-se a escolha da alternativa selecionada a fim de satisfazer às necessidades ou desejos do consumidor

- compra: adquire-se a alternativa selecionada ou um substituto aceitável;

- consumo: utiliza-se a alternativa adquirida;

- avaliação de alternativas pós-compra: verifica-se ograu de satisfação da compra e faz-se uma nova avaliação de acordo com o cumprimento das expectativas;

- descarte: disposição do produto não-consumido ou do que resta dele.

Especificamente em relação ao turismo, Moutinho (1987) considera que o processo de decisão de compra envolve as motivações e intenções do turista, bem como os estímulos que transformam essas intenções em escolha dos produtos ou destinações.

A motivação é um processo de "energização" do indivíduo, tornando-o ativo e dirigindo seu comportamento a um objetivo (Engel et al., 1995). Isso ocorre no reconhecimento de necessidades que, no caso do turismo, podem ser causadas po

Sair da poluição, fugir de problemas) e por motivos de excesso ${ }^{5}$ (diversão, interesses

4. Entende-se por motivos de deficiências aqueles que se relacionam com as motivą̧̃oes de fuga do cotidiano objetivand 4. Entende-se por motivos de deficiências aque local de moradia (Bacal, 1984)

5. Relacionam-se com as motivaçōes de usufruir das férias, com a finalidade de dirigir-se a algum local de interesse (Bacal, 
culturais, congressos cientificos, fazer ou completar cursos, visitar feiras ou exposições, conhecer novos lugares, buscar aventuras amorosas, conviver com a natureza).

Um outro aspecto a ser considerado é que a publicidade e a propaganda também podem representar um estímulo no estágio de reconhecimento das necessidades. Por exemplo: publicidade e propaganda de um país, hotel ou destino em geral, publicações turísticas em revistas, além das sugestões/recomendações de terceiros (comunicação boca a boca).

Após o estágio de reconhecimento das necessidades, o indivíduo inicia a busca por informações, onde ativa o conhecimento arquivado na memória (busca interna) ou procura adquirir informações no ambiente (busca externa). A necessidade e quantidade da busca externa dependem da suficiência ou não da informação interior para uma avaliação satisfatória. Pode ocorrer por falta total de conhecimento interno, como no caso de uma primeira compra, por motivos de obsolescência dos conhecimentos da última compra, por esta ter sido realizada há muito tempo, por um problema de consumo atual diferente do ocorrido durante a última compra ou por motivo de insatisfação com a compra anterior. Portanto, a busca por informações depende do tipo de compra.

Para a compra de um novo produto turístico ou primeira compra, é necessário a busca de muitas fontes de informações, o que torna a decisão mais demorada. Essa tomada de decisão é menos demorada quando já existe um conhecimento prévio sobre a destinação turística. Neste sentido, o comportamento de compra pode ser considerado como rotineiro, quando o turista tem preferências estáveis a respeito de certos destinos, caracterizando-se pela fidelidade ao produto turístico; por exemplo, pessoas que viajam sempre ao mesmo local e que só param de fazê-lo se suas expectativas em relação à destinação deixarem de ser atendidas. Um tipo de compra menos habitual no turismo é a por impulso, pois as atividades turísticas implicam a utilização de uma parcela preciosa do tempo das pessoas (o seu tempo livre), o gasto de dinheiro, geralmente poupado no decorrer do ano para a viagem e $o$ alto envolvimento ocasionado por estes fatores.

A análise das diferentes fontes de informação adquiridas no processo da busca conduz à avaliação das alternativas que podem ser consideradas pelo consumidor sob diferentes aspectos como preço, tempo de permanência no local, distância a ser percorrida, conforto e imagem percebida da destinação. Este processo também sofre influência de questões situacionais como épocas de desemprego, leis específicas, problemas meteorológicos e outros.

$\mathrm{O}$ consumidor também é fortemente influenciado por vários fatores que 0 motivam, como a simpatia ou av0ersão a destinações turísticas, suas atitudes com relação ao seu conhecimento, sentimentos e emoções, o risco percebido na aquisição e as experiências negativas de insatisfações com compras anteriores.

As atitudes apresentadas pelo consumidor variam de acordo com sua extremidade, grau de favorabilidade ou não, a fatores relacionados a um determinado produtoturístico; sua resistência, propensão a mudanças provocadas pelas atividades de marketing; sua persistência, alteração das atitudes no decorrer do tempo; e confiança, crença do consumidor de que suas atitudes estejam corretas.

As motivações e as atitudes do consumidor sofrem influências ambientais, como as apresentadas na Figura 1.

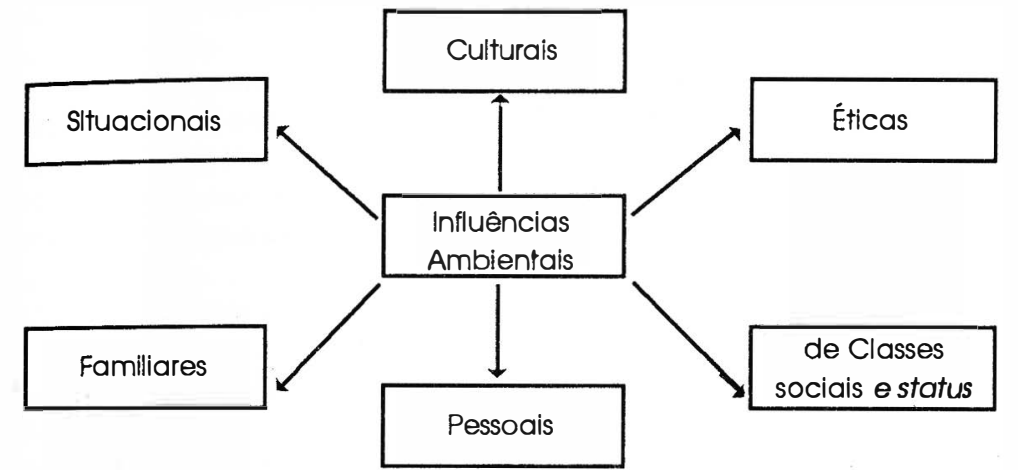

FIGURA I - INFLUENCIAS AMBIENTAIS NAS MOTVAÇÕES E ATIUDES DO CONSUMIDOR

Fonte: Engel et al. (1995).

As influências pessoais relacionam-se aos valores dos indivíduos, estilo de vida, situação econômico-financeira e personalidade. Têm relação com seus grupos de referência, que podem ser formais, possuindo membros definidos, ou informais, com seus membros relacionados por amizade.

A relação desses grupos determina o consumo relacionado ao status (por exemplo, a realização de viagens para ostentá-las aos demais membros do grupo). Esses grupos de referência podem ser primários, em que existe maior interação entre os membros por ser pequeno; ou secundários, em que a interação é mais esporádica. Podem ser grupos de associação, aos quais os indivíduos aspiram associar-se e comportam-se nesse sentido, ou de dissociação, em que pretende-se evitar a associação. Esses grupos também são responsáveis pela troca de informações, a comunicação boca a boca. No caso dos produtos turísticos, esse aspecto é muito importante por caracterizar-se por um recurso muito utilizado no levantamento de informações e na propaganda positiva/negativa de uma destinação feita após a constatação junto a um produto turístico do atendimento ou não das expectativas do consumidor.

As influências familiares referem-se aos diferentes papéis desempenhados pelos membros da família na compra de um determinado produto turístico, em que cada membro da família sofre influências dos demais e têm diferentes papéis na decisão final. É o caso da família que decide viajar para Disneyworld por influência
dos filhos. 
Quanto aos núcleos familiares é necessário fazer-se a distinção também entre os tipos de unidades familiares, como pessoas divorciadas e solteiros, que apresentam comportamentos específicos.

As influências situacionais referem-se à comunicação, compra e situação de uso dos produtos. Essa comunicação caracteriza-se pela exposição ou não do consumidor a comunicações pessoais com outros consumidores ou vendedores ou com propaganda e publicações.

As situações de compra referem-se a fatores predominantes no momento da compra, tais como preço, música, ambientação, cores, ponto de venda, vendedores e outros. No turismo, isso pode ser expresso no momento da compra de um determinado pacote turístico numa agência de viagens, em que o ambiente da agência e a forma de abordagem dos vendedores podem influenciar o comportamento do comprador.

Os consumidores também podem alterar suas compras de acordo com as situações de uso de produtos e o fim ao qual se destinam.

As influências culturais correspondem ao complexo de valores, idéias, artefatos e símbolos que auxiliam o indivíduo a somunicar-se, interpretare avaliarse como membro da sociedade. A cultura é absorvida pela socialização em que o indivíduo desenvolve seus valores, motivações e atividades habituais. A função, a forma e o significado dos produtos são definidos pelo contexto cultural do consumo, determinando o motivo pelo qual as pessoas compram um produto, suas expectativas e os símbolos de significado associados a esses produtos.

Os diferentes grupos culturais têm diferentes informações de preço, qualidade e satisfação em relação aos produtos, de acordo com seus diferentes valores Tais valores podem ser divididos em principais e de transição. Os principais são relativamente permanentes e vinculados a instituições como família, religião educação, designando a forma de uso dos produtos, o que, quando e como consumir aspectos positivos e negativos das marcas (símbolos, pessoas e objetos a elas associadas), as relações de mercado (leis de proteção) e o comportamento ético.

Osvalores, por sua vez, são influenciados por características socioeconômicas e afetam diretamente o tamanho dos segmentos, as diferentes respostas às propagandas, aos serviços prestados e às formas de aquisição. Mudarn conforme a idade, e a geração das pessoas e as próprias instituições mudam, com a família possuindo menor tempo de convívio entre seus membros, a religião diversificando os valores e a escola ocupando mais as funções da família e da religião.

As influências étnicas estão relacionadas a normas e valores de grupos específicos formados de acordo com a nacionalidade, religião, atributos físicos ou região geográfica. Nesse sentido, os grupos étnicos apresentam comportamentos, valores e atitudes diferentes entre si.

A classe social à qual o consumidor pertence também determina seu comportamento. Para a determinação dessas classes, os indivíduos podem ser segmentados pela forma como gastam seus rendimentos e seu tempo, o que, onde e como compram; seus bens de aspiração; status, valores, estilos de vida interesses e comportamentos. Nota-se que, de acordo com as classes sociais, o lazer pode ser realizado de formas diferentes, de acordo com as diferentes formas de atividades dos membros da classe, de acordo com os diferentes grupos de status, e a imagem que se faz da classe social que freqüenta a destinação.

Portanto o modelo de decisão de viagem é baseadoem níveis motivacionais, necessidades e desejos do indivíduo, bem como suas expectativas no momento da decisão da viagem. Conforme o nível de desejo em relação à viagem, o turista pode decisáo dais ou menos sensível à recepção de estímulos tais como propaganda e promoç̃o (atividades de marketing) e outros. O processo decisório será formado de promoça com os determinantes sociais e pessoais do comportamento do turista (personalidade, status socioeconômico, atitudes e valores, grupos de referência e outros). A avaliação das diferentes alternativas de uma viagem incluem a análise de vários fatores (custo/benefício, atrações e amenidades de cada destinação, oportunidades e disponibilidades de viagem). Outros fatores externos, tais como imagem global das alternativas de destinações, experiências de viagem anteriores, condicionantes da viagem (tempo, custo e outros) e o grau de ríscos percebidos (financeiro, funcional, social, físico e psicológico) são importantes determinantes no modelo de decisão da viagem (Moutinho, 1987).

\section{Processo de Compra e Avaliação Pós-Compra no Turismo}

O produto turístico é formado, como já visto, por atrações, facilidades e acessibilidade. Dessa forma, a decisão de compra de um produto turístico é determinada por vários aspectos, como o tipo e o número de atrações, facilidades e acessibilidade que o compõem, que se relacionam às expectativas do turista conforme o típo de viagem que deseja realizar, bem como o tempo disponivel e a quantidade de dinheiro a serem gastos na viagem.

Turistas mais "conservadores" geralmente preferem excursões com hotéis, roteiros e horários determinados, enquanto os mais "aventureiros" descartam totalmente esse tipo de serviço, preferindo determinar sozinhos os roteiros a serem seguidos e a forma de segui-los.

Os motivos, gostos, personalidade e valores dos indivíduos determinarão a importância a ser atribuída a diferentes aspectos da destinação. $\mathrm{O}$ turista pode decidir-se a viajar por vários motivos, como descansar do trabalho, auxiliar a cura de algum problema de saúde, manter maior contato com a natureza, conhecer novas culturas, realizar certos tipos de esportes. Pode preferir diferentes tipos de equipamentos nos hotéis, assim como deslocar-se até o local de avião, ônibus, carro, dependendo da distância.

O tempo disponível para a realização da viagem é outro fator que determina a escolha do turista. As viagens de férias geralmente são mais longas, mais esperadas e mais caras do que as viagens de finais de semana ou feriados, portanto, demandarão maior envolvimento do turista no momento da compra de um pacote ou do estabelecimento de um roteiro, aumentando também o nivel de influência de todos os fatores aos quais encontra-se exposto (familiares, grupos de referência e amigos). 
No momento da compra de um determinado pacote, da reserva de um quarto de hotel ou de um lugar no avião, o turista desenvolve uma série de expectativas em relação à viagem, que tende a aumentar até sua realização. Neste período, que abrange desde o momento da compra até a realização da viagem, o consumidor continua exposto às várias fontes de informação de que dispunha antes e talvez até a novos canais de informação, podendo receber informações "negativas" a respeito da destinação, tornando-se inseguro em relação ao cumprimento das expectativas e alterando sua imagem a respeito do produto turístico.

A partir do início da viagem, vários são os fatores que podem alterar o grau de satisfação do turista, desde a forma de tratamento das aeromoças até problemas com ar condicionado do hotel. A satisfação do turista com cada aspecto da viagem em cada momento formará a satisfação geral do turista pós-compra.

Dependendo do grau de satisfação/insatisfação do turista após seu retorno, ele pode assumir diferentes atitudes e opiniões a respeito da destinação. Pode decidir por retornar ao local ou recomendá-lo a familiares e amigos, se tiver suas expectativas atingidas ou até superadas. Porém, se retornar insatisfeito, podera buscar maior número de fontes de informações antes de realizar a escolha por um outro produto turístico, além de formar uma imagem negativa da destinação enquanto influenciador junto a seus familiares, amigos ou aos grupos aos quais seja referência, ou até mesmo publicar artigos em jornais e revistas relatando os problemas ocorridos na viagem.

Dessa forma, o grau de satisfação do turista pós uso do produto determina a influência que irá exercer nos demais consumidores em potencial, favorecendo ou prejudicando a venda do produto turístico.

\section{Consideraçōes Finais}

Para que um produto turístico tenha sucesso no mercado, concorrendo com as demais destinações, é necessário que se tenha conhecimento sobre os consumidores desse produto. E importante saber ou ter informações sobre:

- os dados demográficos, gostospessoais, atitudes, etc. dos turistas que freqüentam a destinação;

- as formas de lazer que utilizam no dia-a-dia e nos finais de semana;

- os meios de comunicação aos quais encontram-se expostos (jornais, revistas);

- os motivos pelos quais decidiram visitar a localidade;

- o que esperavam no momento da compra do pacote ou reserva do hotel/ passagem; - os aspectos/acontecimentos que o agradaram/desagradaram na viagem desde seu início até o retorno

- os motivos de satisfação/insatisfação com os vários aspectos (passeios locais hotéis, comércio local, restaurantes, serviços de informações, cordialidade e hospitalidade da comunidade local, segurança, limpeza e conservação das ruas, meios de transporte utilizados);

- as razões pelas quais voltariam ou não ao local;

- para que tipo de pessoa recomendariam ou não a destinação (nível de renda personalidade, tipo de unidade familiar, etc.).

Além disso, há necessidade de outros estudos referentes a turistas potenciais, em termos regional, nacional e/ou internacional, visando à captação de outros fluxos turísticos.

Somente o conhecimento dos consumidores do produto turístico pode determinar a realização correta de mudanças ou de al

da localidade, bem como a divulgação adequada nos vários canais de comunıcaçao. Caso contrário, pode-se incorrer em erros envolvendo mudanças ou dando ênfase a aspectos que na verdade não são significativos, ou pior, que irão desagradar 0 turista.

Portanto, uma das fontes de informação que irão nortear o planejamento e o marketing de uma destinação deverá ser o estudo do comportamento do consumidor ou seja, o estudo dos turistas atuais e/ou potenciais que visitarão a localidade. Assim recomenda-sc atenção maior a essa questão, o que, certamente, envolve a realização de estudos e pesquisas específicas sobre a demanda turística

\section{Bibliografia}

ACERENZA, Miguel. 1991. Promoção turistica: um enfoque metodológico. São Paulo: Pioneira. ARREBOLA, José Luis Santos. 1983. La decisión de compra del turista-consumidor. Estudios Turisticos, Madrid, n. 79. ACAL, Sarah S. 1984. Pressupostos do comportamento turistico: influências psicológicas, sócio-culturais e económicas. São Paulo: ECA-USP. Tese de doutorad.

CROMPTON Thunn. 1979. O compontamento do consumidor . São Paulo: Atlas. Annals of Tourism Research, v. $6, \mathrm{n} .4$ . Paul D. 1995. Consumer Behavior. Dryden Press. Paulo: Atlas.

LAGE, Beatriz H. G.; MIILONE, Paulo C. 1991 . Economia do turismo. Campinas: Papirus.

MOUTINHO, Luiz 1987. Consumer Behavior in Turism. European Journal of Marketing, v. 21, n. 10.

RUSCHMANN, Dóris Van De Meene. 1991. Marketing turistico: um enfoque promocional Campinas: Papirus. 